\title{
BEMPS -
}

Bozen Economics \& Management Paper Series

NO 04 / 2013

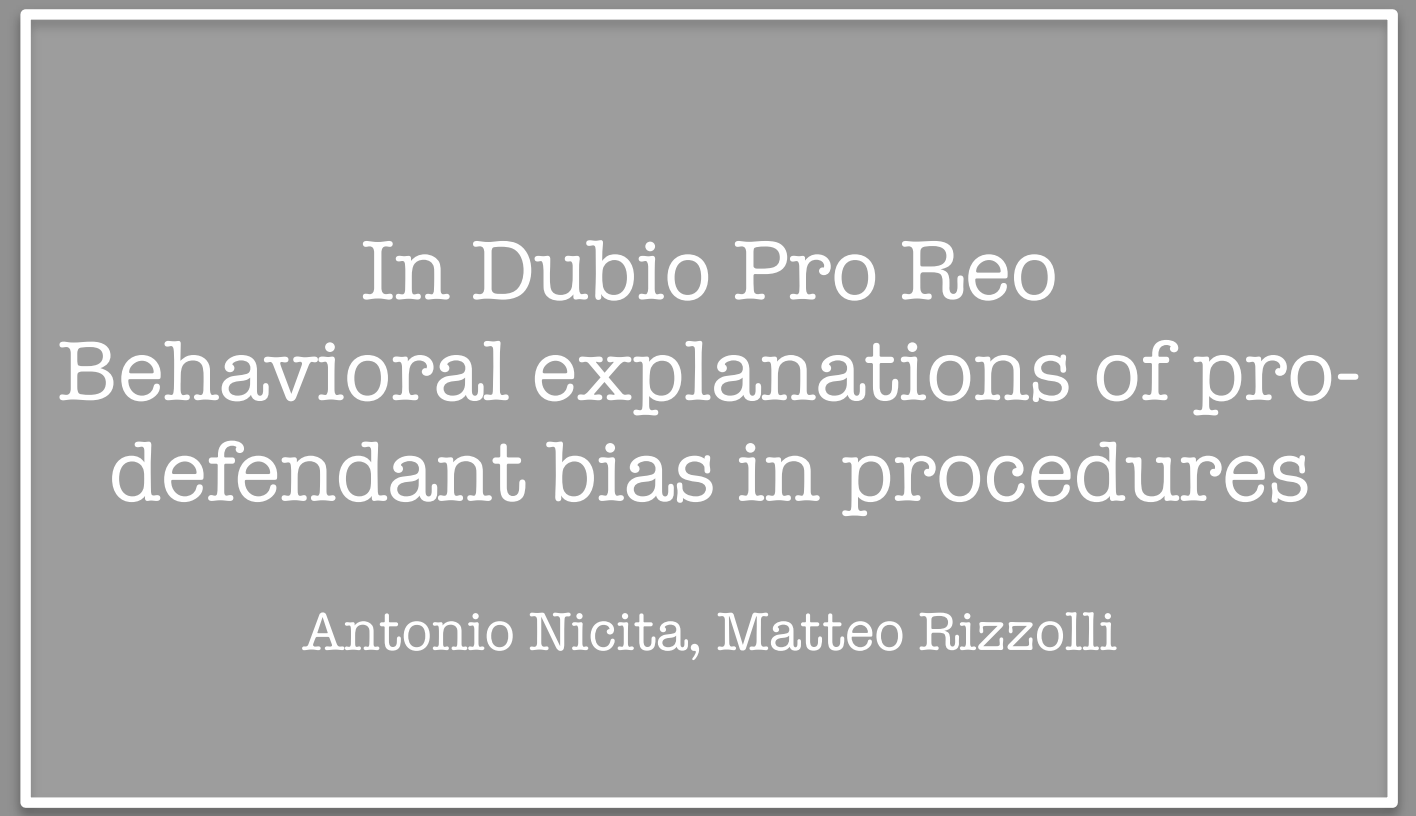




\title{
In Dubio Pro Reo Behavioral explanations of pro-defendant bias in procedures
}

\author{
Antonio Nicita*and Matteo Rizzolli ${ }^{\dagger}$
}

\begin{abstract}
The standard model of optimal deterrence predicts that the probability of wrongful conviction of the innocent is, at the margin, as detrimental to deterrence as the probability of wrongful acquittal of guilty individuals. We extend the model in several directions: using expected utility as well as non-expected utility to consider the role of risk aversion, non-linear probability weighting and loss aversion. We also consider how relevant emotions such as guilt, shame and indignation play out. Several of these factors support the intuition that wrongful convictions of the innocent do have a larger detrimental impact on deterrence and thus the policy implications are reconciled with the widely shared maxim in dubio pro reo. We then draw some theoretical implications such as a novel justification for the different standards of proof in criminal vs civil law as well as other policy implications.
\end{abstract}

Keywords: wrongful convictions, Type I errors, wrongful acquittals, Type II errors, evidence, optimal under-deterrence, behavioral economics, risk aversion, loss aversion, prospect theory, prelec function

JEL classification: K14, K41, K42.

${ }^{*}$ Department of Economics and Law, La Sapienza University of Rome. Via del Castro Laurenziano 9, 00185 Rome. E-mail:antonio.nicita@uniroma1.it

${ }^{\dagger}$ School of Economics, Free University of Bozen - Bolzano. Universitätsplatz 1, 39100 Bozen-Bolzano. E-mail:matteo.rizzolli@unibz.it 


\section{Introduction}

The standard model of optimal deterrence advances some well-known predictions on the impact of judicial errors of both types (wrongful convictions and wrongful acquittals) on deterrence. The model shows that they are both detrimental to deterrence and - more interestingly for us - that they are both equally costly in terms of lost deterrence. Hence, a wise social planner should care about wrongful convictions no more than he cares about wrongful acquittals. This is contrary to the common wisdom, to centuries of legal scholarship and to the actual construction of modern legal procedures, which all seem to hint at the fact that wrongful convictions are much worse mistakes than wrongful acquittals. There are a number of rival explanations of why this is the case. Some of them are collected in the literature review and some new ones are developed in the following sections.

The explanations provided in this paper are all based on more sophisticated models of behavior than the rational self-interested and emotionally neutral agent assumed in the standard model. We first introduce expected utility. We show that, in the presence of monetary gains from crime, standard risk aversion (derived by decreasing marginal returns of income) makes wrongful convictions at the margin more detrimental to deterrence than wrongful acquittals. We also introduce probability weighting with rank-dependent expected utility and show that, under the reasonable condition that the distribution of probability of correct acquittal stochastically dominates the distribution of probability of wrongful acquittal, overweighting small probabilities exacerbates the adverse effect of wrongful convictions on deterrence. Then we introduce loss aversion (through a simplified version of cumulative prospect theory) and show that, wrongful convictions being entirely in the domain of losses, they bring far more disutility to individuals and thus have a larger detrimental impact to deterrence than wrongful acquittals.

We also look at how emotions play out vis-à-vis crime and conviction. We consider three emotions: a) the guilt borne by the culpable (independent of whether he is correctly convicted or wrongfully acquitted); the shame borne by the convicted (independent of whether he is correctly convicted or wrongfully convicted): and indignation borne by the wrongfully convicted. In the last section we draw some policy implications, the most relevant of which is a robust explanation of why we have different standards of proof for civil vis-à-vis criminal procedures.

\section{Literature Review}

The trade-off between the two types of error has been known and discussed by lawyers and philosophers for a long time. Courts make recurrent mention of it and this seems to point at the case of a conscious and intentional, albeit not systematized, pursuit of a specific ratio of innocent persons convicted to guilty persons acquitted that is more favorable to the innocent. How much more 
favorable? While every court and scholar would agree that it is desirable to reduce the number of wrongful convictions, how many more wrongful acquittals are we willing to tolerate in order to achieve this goal? Every American student of law learns by heart Judge Blackstone's maxim that it is Better that ten guilty persons escape than that one innocent suffer (1769). The United States Supreme Court has recalled Blackstone's principle although it has never committed to such a precise number ${ }^{1}$. Countless scholars have mentioned a precise number for this trade-off; however, as Volokh (1997) has pointed out, there is a great variety of opinions on what the number should be. Volokh finds mentions of the error trade-off (wrongful convictions/wrongful acquittals) that date back to the book of Genesis ${ }^{2}$ and historically vary at least between $1,000^{3}$ and $1^{4}$. Blackstone's famous maxim asserts that the optimal tradeoff must be greater than $10 .{ }^{5}$ However this is a severe underestimation if compared to, for instance, Benjamin Franklin's figure ${ }^{6}$ and some other wildly inflated numbers mentioned in the literature ${ }^{7}$. Irony aside, the pro-defendant error ratio in its extremely variegated declinations expresses the principle that it is better that in dubio pro reo. Another way of making this point is to argue, as Posner (1999) does, that the costs of convicting the innocent far exceed the benefits of convicting one more guilty individual and this may be due to a number of reasons.

So why is the maxim that gives this paper its title puzzling for law \& economics? Becker (1968) kicked off the economic analysis of crime deterrence arguing inter alia that in order to achieve optimal deterrence, wrongful acquittals (that is to say undetected crimes) should be compensated by higher sanctions. Harris (1970) extended the model to consider also wrongful convictions. However, Png (1986) was the first to show the detrimental effects of wrongful convictions on deterrence. His argument is based on the simple notion that wrongful acquittals increase the payoff of engaging in the unlawful activity whereas wrongful convictions decrease the payoff of not committing the unlawful act. Both errors are thus equally bad to deterrence and cost the same to society. Since then this extension has been incorporated in the main surveys of

\footnotetext{
${ }^{1}$ The Supreme Court cited Blackstone in "Coffin v. U.S"., 156 U.S. 432 (1895). For direct mention of the trade-off see for instance "Herny v. United States" 61 U.S. 98 (1959): "It is better, so the Fourth Amendment teaches, that the guilty sometimes go free than that citizens be subject to easy arrest", or the concurrent opinion of Judge Harlan in "In re Winship" 397 U.S. 358 (1970) where he states: "I view the requirement of proof beyond a reasonable doubt in a criminal case as bottomed on a fundamental value determination of our society that it is far worse to convict an innocent man than to let a guilty man go free".

2Judge Blackstone's quotation in the title is a reference to Genesis 18:23-32.

${ }^{3}$ Moses Maimonidies, a Jewish Spanish legal theorist, interpreting the commandments of Exodus. Cited in Volokh (1997).

${ }^{4}$ Justinian's Digest. 48.19.5pr. (Ulpianus 7 de off. procons.) sed nec de suspicionibus debere aliquem damnari divus traianus adsidio severo rescripsit: satius enim esse impunitum relinqui facinus nocentis quam innocentem damnari. Also cited in Volokh (1997).

${ }^{5}$ it is better that ten guilty persons escape, than that one innocent suffer (Blackstone, 1769).

6"it is better [one hundred] guilty Persons should escape than that one innocent Person should suffer". Letter from Benjamin Franklin to Benjamin Vaughan (Mar. 14, 1785), in Franklin and Smyth (1970) cited in Volokh (1997).

${ }^{7}$ See also Reiman and van den Haag (1990).
} 
the subject (See Kaplow, 1994; Garoupa, 1997; Polinsky and Shavell, 2009).

On one hand thus we have consistent evidence that adjudicative procedures are built with strong pro-defendant biases that tilt the error's tradeoff away from wrongful convictions even at the cost of more wrongful acquittals and on the other hand we have the simple intuition that optimal deterrence may imply more balanced errors-tradeoff.

To dispense with this puzzle, most papers assume that wrongful convictions cost more than wrongful acquittals because of some ethical costs grounded in deontological reasonings: so that convicting the innocent is inherently bad and morally repugnant. Moreover some of these works dispense altogether with the consequences of a pro-defendant error ratio $^{8}$ on deterrence and consider the optimization of the standard of evidence only in terms of i) expenditure by defendants (Rubinfeld and Sappington, 1987); ii) different fact-finding procedures (Davis, 1994) and technologies (Sanchirico, 1997); and above all iii) the optimization of the exogenously defined moral costs of the two errors (Miceli, 2009). Other authors incorporate deterrence concerns and explain the high standard of evidence in terms of iv) parties' overcompliance (Craswell and Calfee, 1986); v) biased evidence selection (Schrag and Scotchmer, 1994); vi) parties' evidence production expenditure (Yilankaya, 2002); vii) the optimal exercise of care by parties (Demougin and Fluet, 2006); and viii) marginal deterrence (Ognedal, 2005).

Although the standard model claims that the two errors are equally costly in terms of lost deterrence, other papers show that they imply different costs of other kinds. For instance Rizzolli and Saraceno (2013) elaborate on the costs attached to wrongful convictions by non-monetary sanctions; Lando (2009) add also the ethical costs of both setting the guilty free and of punishing the innocent; Galbiati and Garoupa (2007) introduce the stigma costs of wrongful convictions. Hylton and Khanna (2007) develop a public-choice account of the pro-defendant mechanisms in criminal procedure that affect the error ratio as a set of safeguards against the prosecutor's potential misconduct. In their view the pro-defendant error ratio is the result of a second-best equilibrium achieved within the constraint of an irreducible inclination of prosecutors to over-convict defendants (for various public-choice reasons). Persson and Siven (2007) formulate a general equilibrium model of crime deterrence where the pro-defendant error ratio for capital punishment emerges endogenously as a result of a median voter mechanism applied to the courts. Both models depart from the standard model of deterrence. This paper however shows that, besides all these other explanations, and contrary to the claim of the standard model, wrongful convictions do have an asymmetric impact on deterrence and this is due to some intuitive extensions of the economic model.

\footnotetext{
${ }^{8}$ On the difference between the error ratio and the standard of evidence, see Allen and Pardo (2007); Allen and Laudan (2008).
} 


\section{Production of errors and social welfare}

Let us first develop the model under the straightforward assumption of risk neutrality. So let $y_{0}$ be the initial endowment (equal for all agents) and $b$ the benefits of committing the crime. $b$ is distributed among the agents with a generic distribution $z(b)$ and a cumulative $Z(b)$ with support $[0, \bar{B}]$. Let also $h$ be the harm/externality generated by the crime ${ }^{9}$.

For the sake of simplicity, all individuals are detected and brought in front of an adjudicative authority ${ }^{10}$. The authority observes the amount of incriminating evidence $e$ that is produced against the defendant and if this overcomes a certain threshold $\tilde{e}$ then the defendant is sentenced to pay the sanction $s$. For the sake of our argument we maintain the sanction fixed throughout the paper and the social planner optimizes deterrence only by affecting the threshold $\tilde{e}^{11}$. The evidence is stochastically distributed, albeit in general more incriminating evidence is available against guilty individuals than against innocent ones. Therefore let $e$ have a frequency distribution of $a_{i}(e)$ for the innocent and of $a_{g}(e)$ for the guilty where the $i$ subscript stands for innocent and the $g$ stands for guilty. Let $A_{i}(e)$ and $A_{g}(e)$ be the cumulative distributions of $a_{i}(e)$ and $a_{g}(e)$ respectively and note that $A_{i}(\tilde{e})$ and $A_{g}(\tilde{e})$ are the probabilities of being acquitted for the innocent and for the guilty respectively given the threshold evidence level $\tilde{e}$.

Note also that $A_{g}$ is the probability of erroneous acquittal of the guilty and $1-A_{i}$ is the probability of erroneous conviction of the innocent. Note that, if the level of evidence necessary to reach the conviction $\tilde{e}$ is the main policy variable (the social planner can impose different burdens of evidence), then an increase in $\tilde{e}$ generates both an increase in the number of wrongful acquittals and a decrease in the number of wrongful convictions.

Assumption 1. $\left.A_{i}(e)>A_{g}(e) \forall e \in\right] 0, e_{\max }\left[\right.$. Or $A_{i}(\tilde{e})$ first order stochastically dominates $A_{g}(\tilde{e})$.

This assumption simply imposes that on average, it is more likely to accumulate enough evidence to reach a verdict of guilt when the defendant is actually guilty than when the defendant is innocent. If this were not the case and evidence were produced randomly for the innocent and the guilty alike, then the whole criminal procedure aimed at distinguishing guilt from innocence would makes no sense at all.

\footnotetext{
${ }^{9}$ One can think of this crime has having no specific victim but the harm is inflicted upon the society as a whole. An example of such a victimless crime is insider trading.

${ }^{10}$ Adding here a police agency that could detect crime with some $p$ probability of detection would not change the results as long as the detection was random. See also Mookherjee and Png (1992). See further discussion of this point in Rizzolli and Saraceno (2013).

${ }^{11}$ The assumption can be easily relaxed in line with all the main literature on deterrence (Polinsky and Shavell, 2009) without affecting the main findings of the paper
} 


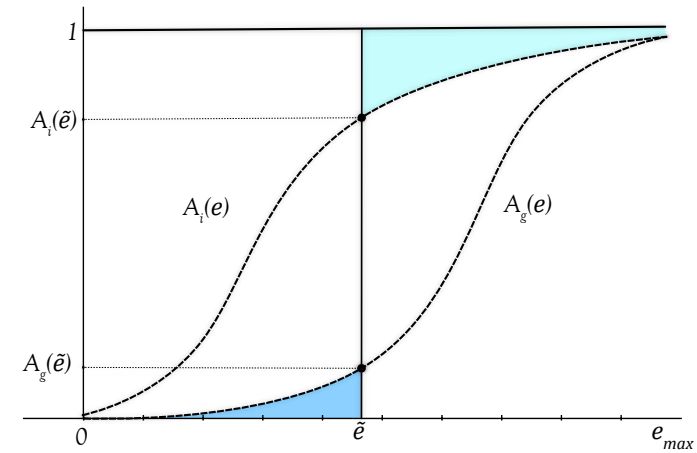

Figure 1: Cumulative distribution of the probabilities of acquittals under the assumption of fosd

Definition 1. Deterrence condition. The individual does not commit the crime as long as the returns/utility from the criminal activity are below the expected returns/utility of refraining from committing the crime.

Definition 2. The crime trigger. Define $\tilde{b}$ as the level of gains from crime above which the deterrence condition does not hold and for which the commission of crime is triggered.

For the sake of simplicity, we also assume that there is no welfare-improving crime as in Becker (this would be a crime for which $b>h)^{12}$ and that sanctions are transferred from the convicted individual to society. In the function of social costs we do not consider the private benefits from crime ${ }^{13}$ but only its social costs. Therefore social welfare is:

$$
S W=\int_{\widetilde{b}}^{\bar{B}} z(b) h d b
$$

or simply $(1-Z(\tilde{b})) h$. The social welfare boils down to the social costs of harm caused by those individuals for which the deterrence condition is not met. This will be the same for all the subsequent extensions of the model. The amount of social harm ultimately depends on the crime rate $(1-Z(\tilde{b}))$ and therefore on $\tilde{b}$. However, the value of $\tilde{b}$ depends on the behavioral assumptions we make concerning the individual choice to commit crime.

On the other hand and since the sanction is fixed by assumption, the social planner affects social welfare only by modifying the threshold $\tilde{e}$ which implicitly defines the error's tradeoff. The choice of the threshold $\tilde{e}$ is thus the channel

\footnotetext{
${ }^{12}$ See further discussion of this point in Rizzolli and Saraceno (2013).

${ }^{13}$ Whether private benefits of crimes should be computed in the social welfare function is the subject of a long-lasting debate. See Rizzolli and Saraceno (2013)
} 
through which the social planner optimizes the social welfare function given individuals' preferences for any given errors' tradeoff. Therefore the social welfare function described by Equation 1 will not change in the remaining of the paper; but we will show how different assumptions about individual behavior under uncertainty lead to different values of the crime trigger $\tilde{b}$ and in particular, we will show how the different errors' tradeoffs that emerge once different behavioral assumptions are set affect the level of $\tilde{b}$.

\subsection{Error tradeoff under risk neutrality}

Each agent decides whether to stay honest or to commit the crime based on its own returns as follows:

$$
\left\{\begin{array}{l}
E \pi_{i}=y_{0}-\left(1-A_{i}\right) s \\
E \pi_{g}=y_{0}+b-\left(1-A_{g}\right) s
\end{array}\right.
$$

The deterrence condition for Equation 2 is satisfied if $E \pi_{i} \geq E \pi_{g}$. From this equation we derive the crime trigger $\tilde{b}_{r n}$ under risk-neutrality, that is to say the benefit's threshold above which the individual will commit the crime:

$$
\tilde{b}_{r n}=\left(1-\left(1-A_{i}\right)-A_{g}\right) s
$$

Proposition 1. Under risk neutrality wrongful convictions $\left(1-A_{i}\right)$ and wrongful acquittals $\left(A_{g}\right)$ have the same detrimental impact on the crime trigger and thus on the deterrence condition.

Note that any change in either wrongful convictions $\left(1-A_{i}\right)$ or wrongful acquittals $\left(A_{g}\right)$ have the same symmetric impact on deterrence. A marginal change in either $1-A_{i}$ or $A_{g}$ determines an equal decrease of $\tilde{b}$. This is because on one hand wrongful acquittals undermine deterrence inasmuch as they decrease the probability of guilty individuals being finally convicted. On the other hand wrongful convictions increase the costs of staying honest and thus decrease the relative costs of committing the crime (Png, 1986). With risk neutrality, in terms of deterrence, one further innocent person convicted is as costly as one further guilty person acquitted. This is where the standard model of deterrence stops (Polinsky and Shavell, 2007, section 15, where they elaborate only the risk-neutral case)

Now that the crime trigger is defined, we can plug it into Equation 1 and thus derive the social welfare with respect to the standard of evidence.

$$
\frac{\partial S W}{\partial e}=\partial\left(1-Z\left(\tilde{b}_{r n}\right)\right) h=-z\left(\tilde{b}_{r n}\right)\left(a_{i}(\tilde{e})-a_{g}(\tilde{e})\right) s h
$$

Proposition 2. Under risk neutrality, the optimal standard of evidence $\tilde{e}$ that minimizes social costs is implicitly defined by $a_{i}(\tilde{e})=a_{g}(\tilde{e})$. 
By looking at Equation 3, a "deterrence effect" à la Becker (1968) can be identified. Note that $\tilde{b}$ increases with the sanction $(\uparrow s \Rightarrow \uparrow \tilde{b})$. Furthermore an "underdeterrence effect" of judicial acquittals of guilty individuals can be observed: $\tilde{b}$ decreases when the probability of mistaken acquittal increases $\left(\uparrow A_{g} \Rightarrow \downarrow \tilde{b}\right)$. Similarly a "compliance effect" of wrongful convictions is identifiable, because $\tilde{b}$ increases when correct punishment increases - and thus wrongful convictions decrease $\left(\uparrow A_{i} \Rightarrow \uparrow \tilde{b}\right)$. Finally, a "screening effect" can be established.

Definition 3. Define $\Delta(\tilde{e})=A_{i}(\tilde{e})-A_{g}(\tilde{e})$ as the accuracy of the adjudicative procedure.

$\Delta(\tilde{e})$ represents the ability of the court to distinguish innocent from guilty individuals: the better the court can discriminate, the greater the advantages of staying honest $(\uparrow \Delta(.) \Rightarrow \uparrow \tilde{b})$.

Definition 4. Define the neutral error's trade-off produced by the accuracy level $A_{i}(\tilde{e})-A_{g}(\tilde{e})$ for which $a_{i}(\tilde{e})=a_{g}(\tilde{e})$.

Accuracy reaches its maximum level when the social planner chooses $\tilde{e}_{\text {neutral }}$ so that the distance between the two cumulative functions is maximized and the sum of the two errors $A_{i}(\tilde{e})-A_{g}(\tilde{e})$ is minimal. This happens for $a_{i}(\tilde{e})=a_{g}(\tilde{e})$.

Definition 5. Define the pro-defendant error's trade-off produced by the accuracy level $A_{i}(\tilde{e})-A_{g}(\tilde{e})$ for which $a_{g}(\tilde{e})>a_{i}(\tilde{e})$.

If the social planner chooses an higher standard of evidence $\tilde{e}_{\text {pro-defendant }}>$ $\tilde{e}_{\text {neutral }}$ than the error tradeoff tilts in favor of the defendant as the probabilities of both correct and wrongful acquittals $-A_{i}(\tilde{e})$ and $A_{g}(\tilde{e})$ respectively- increase. $\tilde{e}_{\text {pro-defendant }}>\tilde{e}_{\text {neutral }}$ necessarily also implies $a_{g}(\tilde{e})>a_{i}(\tilde{e})$ by definition of the frequency distribution of $a_{i}(e)$ and $a_{g}(e)$. Notice that in this case accuracy is not maximal.

\subsection{Wrongful convictions and the error's tradeoff}

Lando (2009) explicitly rules out that wrongful convictions lower deterrence and consider only the probability of wrongful acquittals. Lando's crime trigger is thus $\tilde{b}_{L}=\left(1-A_{g}\right) s$. While Lando acknowledges the possibility of wrongful convictions of innocents $\left(1-A_{i}\right)$ and shows how they play a role vis-à-vis the other types of social costs, he neglects that they have a role in defining $\tilde{b}_{L}$. This is because -Lando argues- at least for a certain set of crimes, wrongful convictions have no incentive effect on the decision to commit the crime. Lando's point is extensively spelled out in his 2006's work. Some objections to this thesis are addressed elsewhere (see Garoupa and Rizzolli, 2013). Here we limit ourself to point out what we believe is a strong implication of assuming that wrongful convictions do not affect deterrence.

Proposition 3. If wrongful convictions do not affect deterrence (as Lando 2006 and 2009 argue), the standard of evidence that maximizes social welfare is equal to zero. 
By deriving the social welfare with respect to $e$ in order to obtain the optimal standard of evidence that maximizes social welfare we run into a problematic result. In fact $\frac{\partial S W}{\partial e}=\partial\left(1-Z\left(\tilde{b}_{L}\right)\right) h=-z(\tilde{b})\left(a_{g}(\tilde{e})\right) s h$. Now, notice that: i) $s>0$; ii) $\left.a_{g}(\tilde{e})>0 \forall e \in\right] 0, e_{\max }\left[\right.$ where $e_{\max }$ is the level of $e$ for which $A_{g}=1$ and iii) $z\left(\tilde{b}_{L}\right)>0$. This implies that $\tilde{e}^{*}$ has a corner solution with $\tilde{e}^{*}=0$. The standard of evidence that thus minimizes crime is equal to zero. It is easy to see why: in fact with $\tilde{e}=0$ then $A_{g}(\tilde{e})=0$ (no criminal is acquitted) and $1-A_{i}(\tilde{e})=1$ (all innocents are convicted). Social welfare is certainly maximized but the result is strikingly paradoxical as the solution to crime is to punish everybody independently on actual guilt.

Contrary to Lando's work in the present social cost function only the deterrence costs are considered. Lando's results seem more plausible once the costs of convictions and the ethical costs mentioned by Lando and not considered here are also analyzed. However notice that there might exists adjudicative procedures for which these costs are simply not relevant. Think for instance to an adjudicative procedure that does not involve neither conviction costs (only monetary sanctions are applied) nor ethical costs (for instance it is an administrative sanction with little stigma attached (Rasmusen, 1996; Galbiati and Garoupa, 2007)).

\subsection{Error tradeoff under expected utility}

Now let us introduce expected utility and risk aversion. Expected utility in the deterrence framework has been considered by Polinsky and Shavell (1979); Dacey and Gallant (1997); Dhami and al Nowaihi (2010). However, they did not consider wrongful convictions in their models. We have to distinguish two cases:

- The gains from crime have a monetary nature (as in case of theft or robbery) and therefore are subject to decreasing marginal returns of income.

- The gains from crime have a non-monetary nature (such as in case of homicide)

\subsection{Monetary gains from crime}

We consider $b$ as an amount of money to be gained from committing the crime and from which utility $U($.$) can be derived. The utility of the action choices$ available (staying law-abiding or committing crime) are respectively the following

$$
\left\{\begin{array}{l}
E U_{i}=A_{i} U\left(y_{0}\right)+\left(1-A_{i}\right) U\left(y_{0}-s\right) \\
E U_{g}=A_{g} U\left(y_{0}+b\right)+\left(1-A_{g}\right) U\left(y_{0}+b-s\right)
\end{array}\right.
$$

The deterrence condition imposes that $E U_{i} \geq E U_{g}$. Rearranging Equation 5 we obtain: 


$$
\begin{aligned}
A_{i}\left[U\left(y_{0}\right)-U\left(y_{0}-s\right)\right]-A_{g}\left[U\left(y_{0}+b\right)-\right. & \left.U\left(y_{0}+b-s\right)\right] \\
& \geq U\left(y_{0}+b-s\right)-U\left(y_{0}-s\right)
\end{aligned}
$$

which implicitly defines the crime triggers $\tilde{b}_{e u}$ once we impose $E U_{i}=E U_{g}$.

Proposition 4. Under risk aversion, when the gains from crime have a monetary nature, wrongful convictions $\left(1-A_{i}\right)$ create more disutility and thus are more detrimental to the deterrence condition than wrongful acquittals $\left(A_{g}\right)$ and therefore social costs are minimized in presence of a pro-defendant error's tradeoff with $a_{g}(\tilde{e})>a_{i}(\tilde{e})$.

Equation 6 shows that both $1-A_{i}$ and $A_{g}$ jeopardize deterrence as before. This is because when there is an increase in either of the errors (increase in $A_{g}$ or decrease in $A_{i}$ ) on the left-hand side of the equation, individuals find crime convenient for lower levels of $b$ (on the right-hand side). However, given the concavity of the utility function, the negative impact of wrongful convictions $\left(1-A_{i}\right)$ on the crime trigger $\tilde{b}_{e u}$, and thus on social welfare is stronger than that of wrongful acquittals $\left(A_{g}\right)$.

To see why, note that $U\left(y_{0}\right)-U\left(y_{0}-s\right)>U\left(y_{0}+b\right)-U\left(y_{0}+b-s\right)$. In order to maintain the same level of deterrence, a given percentage increase of $1-A_{i}$ must be compensated by a smaller percentage decrease of $A_{g}$.

The introduction of expected utility in the model affects how the crime trigger $\tilde{b}_{e u}$ is computed but does not affect the shape of the social welfare function that remains the same and equal to $\left(1-Z\left(\tilde{b}_{e u}\right)\right) h$. While it is not possible to make direct comparative statistics given the different nature of the utility function, it is worth noticing that, once risk-aversion is introduced, the sanction is no longer a costless transfer but it implies a social loss embodied by the risk premium ${ }^{14}$ (see Garoupa, 2001). Both errors -as they happen with some probability- imply this risk-premium cost but, ceteris paribus, this social loss is larger in case of erroneous convictions of innocents following 4. This in turns implies that social welfare is maximized by choosing a standard of evidence that implies a pro-defendant error's tradeoff $\left(a_{g}(\tilde{e})>a_{i}(\tilde{e})\right)$.

\subsection{Non-monetary gains from crime}

When the gains from crime do not have a monetary nature, the results are very similar to those in Proposition 1 once we assume separability in the arguments (monetary vs. non-monetary payoffs). The utility of the action choices available (staying law-abiding or committing crime) are respectively the following:

\footnotetext{
${ }^{14}$ In Appendix 7.1 we compute the difference in utility of the two errors as the risk premium calculated with the Arrow-Pratt Absolute Risk Aversion. This allows for some rudimentary welfare comparison between the case with monetary payoffs and the case with monetary payoffs and risk aversion.
} 


$$
\left\{\begin{array}{l}
E U_{i}=A_{i} U\left(y_{0}\right)+\left(1-A_{i}\right) U\left(y_{0}-s\right) \\
E U_{g}=A_{g} U\left(y_{0}\right)+\left(1-A_{g}\right) U\left(y_{0}-s\right)+b
\end{array}\right.
$$

The deterrence condition imposes that $E U_{i} \geq E U_{g}$. This produces a definition of the crime trigger as follows:

$$
\tilde{b}=\left(A_{i}-A_{g}\right)\left[U\left(y_{0}\right)-U\left(y_{0}-s\right)\right]
$$

The individual will commit the crime as long as his non-monetary gain from crime is higher than the net disutility of the sanction discounted by both judicial errors.

Proposition 5. Under expected utility, when the gains from crime are nonmonetary, wrongful convictions and wrongful acquittals are equally detrimental to the deterrence condition and therefore the optimal standard of evidence $\tilde{e}$ that minimizes social costs implies a neutral error's tradeoff with $a_{i}(\tilde{e})=a_{g}(\tilde{e})$.

As for the case of monetary payoffs and risk-neutrality, any change in either wrongful convictions $\left(1-A_{i}\right)$ or wrongful acquittals $\left(A_{g}\right)$ has the same symmetric impact on deterrence because any marginal change in either $1-A_{i}$ or $A_{g}$ determines an equal decrease of $\tilde{b}$.

\section{Judicial errors and non-expected utility}

The standard model of optimal deterrence is usually developed under the assumption of risk-neutrality or at most of standard risk aversion within the expected utility framework. However there exists a vast literature showing that risk aversion derived from the expected utility framework has failed to account for a large amount of field data evidence and experimental evidence (Kahneman, 2003; Kahneman et al., 1990) in a variety of realms. It all thus make sense to extend the standard model of optimal deterrence as well to account for non-expected utility theories of behavior ${ }^{15}$.

One important violation concerns the stylized fact that individuals tend to overweight low-probability events such as winning the lottery, or suffering a disastrous insurable loss.

One further important violation concerns people's tendency to strongly prefer avoiding losses to acquiring gains. This behavioral trait is universally known as loss aversion (Kahneman et al., 1991). Expected utility cannot explain this

\footnotetext{
${ }^{15}$ It should be noted that economic theories of behavior, including non-expected utility theories, have the ambition of explaining behavior under generic circumstances and as such they are based on increasingly sophisticated but realistic assumptions concerning behavior in general; within this framework the choice of committing crime is simply one of many specific choices that the individual faces. This approach creates a gulf between such theories and some criminological theories of behavior which are more focused on explaining particular traits or tendencies of individuals more inclined to commit crime.
} 
behavior as it predicts that individuals should objectively weight low probabilities and should only care about absolute payoffs. A number of "non-linear expected utility theories" have emerged to overcome the shortcomings of expected utility. The idea of applying models of non-expected utility to the Becker paradox is by no mean new. Lattimore and Witte $(1986 ; 1992)$ have considered criminals behavior within prospect theory. Eide (1995; 2011), Neilson and Winter (1997) and Garoupa (2001) extended the standard model to rank dependent expected utility and Dhami and al Nowaihi (2010) and al Nowaihi and Dhami (2010)present a compact survey of the Becker paradox in light of non-expected utility theories of behavior.

All these papers focus on the tradeoffs between severity and probability of punishment in case of wrongful acquittals and all overlook the role played by wrongful convictions. The contribution of the present paper is to use these non-expected theories of utility to cast light on the asymmetric role of wrongful convictions vis-à-vis deterrence and their consequences on the optimal standard of evidence.

\subsection{Non linear probability weighting and Rank-Dependent Expected Utility}

One first conservative extension of the expected utility framework is provided by Quiggin $(1982,1993)$ with his Rank Dependent expected Utility (RDU). With RDU we can address whether individuals' tendency to overweight small probabilities has anything to do with the supposedly low probability of wrongful conviction (vis-à-vis wrongful acquittals).

Suppose that the individual choices can be described via RDU. Define $w$ as the probability weighting function ${ }^{16}$ and let us also assume that the weighting function is the same for the events in the action spaces of both innocent and guilty individuals. Following Quiggin $(1982,1993)$ and Dhami and al Nowaihi (2010, Definition 12) and considering the lottery $\left(x_{1}, x_{2}, \ldots, x_{n} ; p_{1}, p_{2}, \ldots, p_{n}\right)$ that pays $x_{i}$ with probability $p_{i}$, where the possible outcomes of the lottery are ordered from lowest to highest $x_{1}<x_{2}<\ldots<x_{n}$. Define the decision weights under RDU, $\pi_{i}=w\left(\sum_{j=i}^{n} p_{j}\right)-w\left(\sum_{j=i+1}^{n} p_{j}\right)$ where $w($.$) is a prob-$ ability weighting function (more on this later) and thus the decision maker's $\mathrm{RDU}$ is $U\left(x_{1}, x_{2}, \ldots, x_{n} ; p_{1}, p_{2}, \ldots, p_{n}\right)=\sum_{j=1}^{n} \pi_{j} u\left(x_{j}\right)$.

We obtain the result that the two choices of action have the following prospects:

$$
\left\{\begin{array}{l}
R D U_{i}=w\left(A_{i}\right) U\left(y_{0}\right)+\left(1-w\left(A_{i}\right)\right) U\left(y_{0}-s\right) \\
R D U_{g}=w\left(A_{g}\right)\left[U\left(y_{0}\right)+b\right]+\left(1-w\left(A_{g}\right)\right)\left[U\left(y_{0}-s\right)+b\right]
\end{array}\right.
$$

Imposing the deterrence condition leads to the following definition of the crime trigger:

\footnotetext{
${ }^{16}$ Under RDU, infinitesimal probabilities of events are infinitely over-weighted, such that $\lim _{p \rightarrow 0} \frac{w(p)}{p^{\gamma}}=\infty$ for all $\gamma>0$. See Definition 9 in Dhami and al Nowaihi (2010).
} 


$$
\tilde{b}=\left(w\left(A_{i}\right)-w\left(A_{g}\right)\right)\left[U\left(y_{0}\right)-U\left(y_{0}-s\right)\right]
$$

Equation 8 is very similar to Equation 7 except for the fact that now both probabilities of error are weighted by $w($.$) which implies that for small proba-$ bilities of acquittals $w\left(A_{i}\right)>A_{i}$ and $w\left(A_{g}\right)>A_{g}$ while for large probabilities of acquittals $w\left(A_{i}\right)<A_{i}$ and $w\left(A_{g}\right)<A_{g}$. The following graph illustrates the curvature of the probability weighting function as used in Tversky and Kahneman (1992).

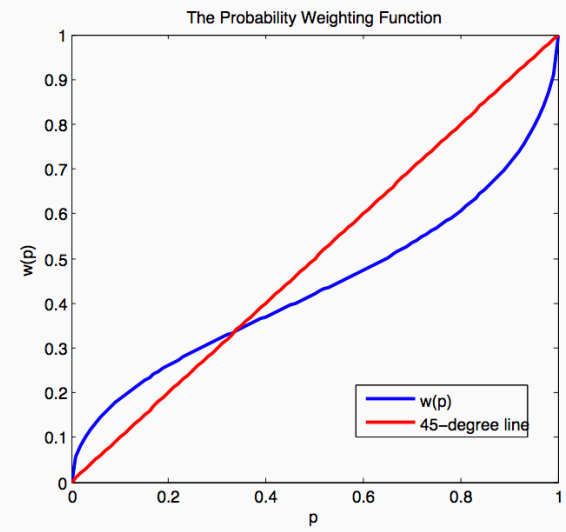

Figure 2: The functional form used by Tversky and Kahneman (1992) with $w(p)=\frac{p^{\gamma}}{\left[p^{\gamma}+(1-p)^{\gamma}\right]^{\frac{1}{\gamma}}}$ with $\gamma=0.61$

To see how RDU affects the deterrence condition, the crime trigger $\tilde{b}$ and the balance of errors we start by recalling Assumption 1, which imposes that $A_{i}(e)>A_{g}(e)$. The individual considers both probabilities of being convicted: $1-A_{i}(e)$ when innocent and $1-A_{g}(e)$ when guilty. For the relatively high level of evidence $\tilde{e}$ required to reach a guilty verdict we know that the probabilities of both wrongful and correct convictions are low and therefore are overweighted because of rank dependent expected utility. However because of the assumption of first order stochastic dominance, it must be true that $1-A_{i}(e)<1-A_{g}(e)$ and therefore wrongful convictions are relatively more overweighted than correct convictions. The intuition is the following: for high levels of $\tilde{e}$, because of $\mathrm{RDU}$ people may tend to overweight the low probability of being wrongfully punished and relatively underweight the higher probability of being correctly punished. If people follow RDU, then an objective decrease in $1-A_{i}$ (which implies a correspondent albeit lower increase in $A_{g}$ ) may imply a severe deterioration of deterrence. In fact, on one hand, the objective probability $\left(1-A_{i}\right)$ of wrongful conviction decreases but this effect is partly offset by the fact that smaller probabilities become increasingly overweighted. On the other hand, the decrease 
in wrongful convictions brings in more wrongful acquittals and, because of the fosd assumption, the effect of the weighting function $w($.$) on this probability is$ lower.

Proposition 6. If individuals overweight small probabilities following $R D U$, then - ceteris paribus - the deterrence condition deteriorates because the detrimental effect of wrongful convictions $\left(1-A_{i}\right)$ is relatively more weighted than the beneficial effect of correct convictions $\left(1-A_{g}\right)$ and therefore the optimal standard of evidence $\tilde{e}$ that minimizes social costs implies a pro-defendant error's tradeoff with $a_{g}(\tilde{e})>a_{i}(\tilde{e})$.

\subsection{Loss aversion and judicial errors}

Another interesting extension concerns the introduction of loss aversion, which is the other major departure from the expected utility framework. In fact people tend to think of possible outcomes of a choice under uncertainty relative to a certain reference point rather than to the final status. As such the observed tendency is for people to prefer the avoidance of losses (outcomes below the reference point) than the acquisition of comparable gains (outcomes above the reference point). Loss aversion is a behavioral concept defined entirely in terms of preferences. Cumulative prospect theory (CPT) accounts for loss aversion and also for the previously mentioned behavioral regularity of over-weighting extreme, but unlikely events and the reflection effect ${ }^{17}$ (Bowles, 2004).

We assume that the reference income for both choices is $y_{r}=y_{0}$ which is the status quo income without crime and errors. We choose a $y_{r}$ such that, if the individual commits the crime and he is punished, he is in the domain of losses $\left(y_{0}-y_{r}+b-s=b-s<0\right)$ while if he is not punished, then he is in the domain of gains $\left(y_{0}-y_{r}+b=b>0\right)$. We follow mainly the definitions $(14,15,16)$ of Dhami and al Nowaihi (2010). A fully-fledged CPT function would envisage some probability weights as in the case of RDU. For our purposes, however, we are interested in the role of loss aversion in isolation of probability weighting. We adopt the Tversky and Kahneman (1992) utility function with the simplification in the exponent introduced by al Nowaihi et al. (2008) ${ }^{18}$ :

$$
V(\arg )= \begin{cases}(\arg )^{\gamma} & \text { if }(\arg ) \geq 0 \\ -\theta(-\arg )^{\gamma} & \text { if }(\arg )<0\end{cases}
$$

with coefficients $0<\gamma<1$ and $\theta>1^{19}$

\footnotetext{
${ }^{17}$ Kahneman and Tversky (1979) observed that when decision problems involve not just possible gains, but also possible losses, people's preferences regarding negative prospects are usually a mirror image of their preferences regarding positive prospects. Simply put, while they are risk-averse over prospects involving gains, people become risk-loving over prospects involving losses. This observation is reflected in the convexity of the value function in the losses.

${ }^{18}$ al Nowaihi et al. (2008) show that preference homogeneity and loss aversion are necessary and sufficient for the value function to have the power form with identical powers for gains and losses and for the probability weighting functions for gains and losses to be identical.

${ }^{19}$ Tversky and Kahneman (1992)estimated $\gamma \approx 0.88$ and $\theta \approx 2.25$
} 
Keeping aside probability weighting, the value functions for the action choices available (staying law-abiding or committing crime) are respectively the following:

$$
\left\{\begin{array}{l}
V_{i}=-\left(1-A_{i}\right) \theta(s)^{\gamma} \\
V_{g}=A_{g} b-\left(1-A_{g}\right) \theta\left[(s)^{\gamma}+b\right]
\end{array}\right.
$$

We keep $b$ out of the (arg) because, following our assumption, it is not a monetary gain and therefore it is not subject to the exponential utility form. Imposing the deterrence condition leads to the following definition of the crime trigger:

$$
\tilde{b}=\left[\frac{A_{g}-\theta\left(1-A_{i}\right)}{A_{g}-\theta\left(1-A_{g}\right)}-1\right](s)^{\gamma}
$$

Because of fosd, $A_{g}-\theta\left(1-A_{i}\right)<A_{g}-\theta\left(1-A_{g}\right)$ and therefore $\tilde{b}>0$ as expected. Moreover it is clear that wrongful convictions are more detrimental to the deterrence condition as they enter the equation with the $\theta$ weight while wrongful acquittals do not.

Proposition 7. With loss aversion, wrongful convictions are even more costly than wrongful acquittals and thus detrimental to deterrence and therefore the optimal standard of evidence $\tilde{e}$ that minimizes social costs implies a pro-defendant error's tradeoff with $a_{g}(\tilde{e})>a_{i}(\tilde{e})$.

\section{Judicial errors and emotions}

Another set of interesting questions concerns how emotions such as guilt and shame influence the decision to commit crime in particular with regard to the possibility of a wrongful conviction. Behavioral and experimental economics has long considered the impact of guilt and shame on behavior (Elster, 1998; de Hooge et al., 2007; Kurzban et al., 2007; Battigalli and Dufwenberg, 2007) and law \& economics has begun to draw some normative implications from these findings (see McAdams and Rasmusen, 2007; Kaplow and Shavell, 2007 among others, although see Mitchell, 2002 for a critique). Emotions can interact in sophisticated ways with decision-making: they can i) induce hyperbolic discounting of future gains (Loewenstein, 2000); act as "action tendencies", which ii) shape preferences over actions vis-à-vis outcomes (Elster, 1998) and iii) play a role as "stabilizers" of individuals" "dispositions to follow rules in the by-presence of opposing situational incentives" (Vanberg, 2008); and iv) be "commitment devices" (Frank, 1988). The modeling of emotions in economic theory is often simplified so as to include emotions as additional (psychological) costs or benefits in the utility function. Emotional costs and benefits enter along with material rewards in the decision calculus. In the context of our paper we specifically focus on guilt, shame and indignation as they all three play a relevant role in the presence of judicial errors and wrongful convictions of the innocent. The 
three emotions apply to different circumstances in accordance with the following table:

\begin{tabular}{|c|c|c|c|}
\hline & \multicolumn{2}{|c|}{ Is the defendant culpable? } \\
\hline & & $\mathrm{Y}$ & $\mathrm{N}$ \\
\hline \multirow[t]{2}{*}{$\begin{array}{l}\text { Is the defendant } \\
\text { convicted? }\end{array}$} & $\mathrm{Y}$ & $\begin{array}{c}\left(1-A_{g}\right) \\
\text { Shame \& Guilt }\end{array}$ & $\begin{array}{c}\quad\left(1-A_{i}\right) \\
\text { Shame \& } \\
\text { Indignation }\end{array}$ \\
\hline & $\mathrm{N}$ & $\begin{array}{l}\left(A_{g}\right) \\
\text { Guilt }\end{array}$ & $\left(A_{i}\right)$ \\
\hline
\end{tabular}

Table 1: How emotions apply to the different possible outcomes

\subsection{Guilt}

Guilt arises in a variety of settings. In bilateral relations guilt arises as a consequence of "the infliction of harm, loss, or distress on a relationship partner" (Baumeister et al., 1994). In public contexts such as our framework, guilt may arise from violating a social norm, from breaking a moral obligation or from committing an offense. It is a cognitive experience that entails emotional costs to the individual and it is usually related to the magnitude of the harm inflicted with the violation. A rational individual with conformist or pro-social preferences thus weighs the costs of guilt in his decision whether to commit crime. Of course guilt may not arise at all in case of a sadist or totally disinhibited individual. Note that the culpable individual suffers guilt independent of whether he is actually punished or not and note also that the innocent defendant wrongfully convicted does not suffer guilt. We thus model the costs of guilt as a function $\psi(h)$ with $\psi^{\prime}, \psi^{\prime \prime}>0$ : the intensity of guilt escalates as the crime becomes graver.

The utility of the action choices available (staying law-abiding or committing crime) are respectively the following:

$$
\left\{\begin{array}{l}
E U_{i}=A_{i} U\left(y_{0}\right)+\left(1-A_{i}\right) U\left(y_{0}-s\right) \\
E U_{g}=A_{g} U\left(y_{0}\right)+\left(1-A_{g}\right) U\left(y_{0}-s\right)+b-\psi(h)
\end{array}\right.
$$

The deterrence condition leads to the following definition of the crime trigger:

$$
\tilde{b}=\left(A_{i}-A_{g}\right)\left[U\left(y_{0}\right)-U\left(y_{0}-s\right)\right]+\psi(h)
$$

Proposition 8. The emotion of guilt borne by culpable individuals (independent of whether they are convicted) implies a higher crime trigger but does not alter the symmetric impact of errors on the deterrence condition and therefore the optimal standard of evidence $\tilde{e}$ that minimizes social costs implies a neutral error's tradeoff with $a_{i}(\tilde{e})=a_{g}(\tilde{e})$ 


\subsection{Shame}

Shame is also a powerful emotion (Nussbaum, 2004) that the defendant may suffer when his conviction becomes common knowledge. Shame is both an emotional cost as well as a tangible cost as the defendant's peers can observe the conviction and they may impose a vast array of shaming sanctions on the individual. There is a consistent literature on shaming sanctions (Massaro, 1997; Kahan and Posner, 1999; Alon and Alon, 2005; Kahan, 2005-2006). Shaming sanctions are informal costs imposed on the shamed by others when they refuse to deal with and in general when they impose costs on the shamed individuals. Elster (1998) argues that the material sanctions themselves are best understood as vehicles of the emotion of contempt, which is the direct trigger of shame. When a person refuses to deal with someone who has violated a social norm, the latter may suffer a financial loss. More important, he will see the sanction as a vehicle for the emotions of contempt or disgust, and suffer shame as a result. Note that shame is suffered both by the guilty as well as by the innocent when they are punished; however, it is not suffered by the guilty who escapes conviction. We model shame as a cost $\delta(h)$ which is a marginally increasing function of the magnitude of the crime's harm for which the individual is convicted $\left(\delta^{\prime}, \delta^{\prime \prime}>0\right)$ : the graver the crime is, the more shameful the related conviction is.

The utility of the action choices available (staying law-abiding or committing crime) are respectively the following:

$$
\left\{\begin{array}{l}
E U_{i}=A_{i} U\left(y_{0}\right)+\left(1-A_{i}\right)\left[U\left(y_{0}-s\right)-\delta(h)\right] \\
E U_{g}=A_{g} U\left(y_{0}\right)+\left(1-A_{g}\right)\left[U\left(y_{0}-s\right)-\delta(h)\right]+b
\end{array}\right.
$$

The deterrence condition leads to the following definition of the crime trigger:

$$
\tilde{b}=\left(A_{i}-A_{g}\right)\left[U\left(y_{0}\right)-U\left(y_{0}-s\right)+\delta(h)\right]
$$

Proposition 9. The emotion of shame borne both by convicted individuals and innocent ones implies a higher crime trigger but does not alter the symmetric impact of errors on the deterrence condition and therefore the optimal standard of evidence $\tilde{e}$ that minimizes social costs implies a neutral error's tradeoff with $a_{i}(\tilde{e})=a_{g}(\tilde{e})$

\subsection{Indignation}

Indignation is an emotion of annoyance or strong displeasure provoked by what is perceived as unfair, unjust, offensive, insulting, or base treatment (Elster, 1998). It is also referred to as righteous anger and this offers a glimpse of why indignation arises in the context of wrongful convictions of innocent individuals. We can model indignation as an emotional cost that arises in the presence of wrongful convictions and it is borne by the innocent unjustly convicted. Define $\phi(h)$ as the cost of indignation and assume $\phi^{\prime}, \phi^{\prime \prime}>0$. 
The utility of the action choices available (staying law-abiding or committing crime) are respectively the following:

$$
\left\{\begin{array}{l}
E U_{i}=A_{i} U\left(y_{0}\right)+\left(1-A_{i}\right)\left[U\left(y_{0}-s\right)-\phi(h)\right] \\
E U_{g}=A_{g} U\left(y_{0}\right)+\left(1-A_{g}\right) U\left(y_{0}-s\right)+b
\end{array}\right.
$$

Imposing the deterrence condition leads to the following definition of the crime trigger:

$$
\begin{aligned}
\tilde{b}=U & \left(y_{0}\right)-U\left(y_{0}-s\right) \\
& \quad-\left(1-A_{i}\right)\left[U\left(y_{0}\right)-U\left(y_{0}-s\right)+\phi(h)\right]-A_{g}\left[U\left(y_{0}\right)-U\left(y_{0}-s\right)\right]
\end{aligned}
$$

Proposition 10. The emotion of indignation borne by innocent individuals wrongfully convicted implies a lower crime trigger. Moreover wrongful convictions have a larger detrimental impact on the crime trigger than wrongful acquittals and therefore the optimal standard of evidence $\tilde{e}$ that minimizes social costs implies a pro-defendant error's tradeoff with $a_{g}(\tilde{e})>a_{i}(\tilde{e})$.

\section{Some theoretical implications}

We have so far established from a theoretical point of view that wrongful convictions bring more disutility than wrongful acquittals under the hypothesis that individuals are risk-averse under both expected and non-expected utility. Why does this matter? We believe that the risk preference explanation of the error bias brings important explanatory implications in at least one respect: it gives a simple intuition of why we have a different burden of proof between civil law and criminal law.

\subsection{The burden of evidence in criminal vs civil law ex- plained by risk preferences}

The burden of evidence - our $\tilde{e}$ - notoriously differs between different branches of the law. With a great degree of simplification we can argue that it is common to find different specifications of the standard of evidence, increasing in their $\tilde{e}$, as follows: i) preponderance of evidence (POE) used in civil law; ii) clear and convincing evidence (CCE) used instead in administrative law; and iii) beyond any reasonable doubt (BARD) in criminal law. The burden of proof required under

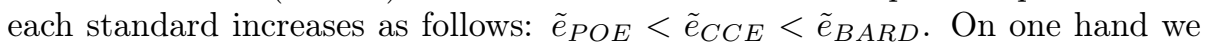
have the POE standard for which a slight prevalence of incriminating over exculpatory evidence can lead to the establishment of guilt by the adjudicative body. On the other hand the BARD standard instead implies that a great amount of evidence must be accumulated before conviction can be reached. The CCE lies somewhere in between. Notoriously the POE standard minimizes the sum of errors (wrongful convictions and wrongful acquittals) while the BARD achieves a 
low tradeoff of wrongful convictions against wrongful acquittals. Moreover, the BARD standard is often defined in terms of the error ratio that it can achieve and the $1 / 10$ ratio is considered a reasonable measure. This is sometimes called the Blackstone error ratio after Judge Blackstone's famous maxim: better that ten guilty escape than that one innocent suffer. ${ }^{20}$

Why do we have these different burdens of proof in different branches of the law? To be sure, there are several rival explanations (Png, 1986; Rubinfeld and Sappington, 1987; Reinganum, 1988; Andreoni, 1991; Miceli, 1991; Schrag and Scotchmer, 1994; Schauer and Zeckhauser, 1996; Posner, 1999; Farmer and Terrell, 2001; Yilankaya, 2002; Demougin and Fluet, 2005, 2006, 2007). However, we believe that risk aversion represents a distinct and novel explanation for it. Risk aversion intended as the decreasing utility of income and derived under the expected-utility framework can be justified only over risks involving large amounts of wealth implying a significant change in expected lifetime income. Rabin and Thaler (2001) give the following example: if an individual is observed to always turn down a 50-50 gamble of losing $\$ 10$ or gaining $\$ 11$, and if we justify this behavior with standard expected-utility risk aversion, then the same individual also must consistently turn down a gamble where there is a 50 per cent chance of losing $\$ 100$ and a 50 per cent chance of winning an infinitely large amount of money. Of course this is an absurd level of risk aversion that makes no sense. Rabin (2000) has developed a theorem to calibrate consistent behavior among small and large bets under standard expected-utility risk aversion ${ }^{21}$.

The calibration theorem however tells us something important for our argument. That risk aversion affects behavior is a reasonably sound assumption for relatively large bets (such that the expected income over a lifetime is affected). This is generically the case of criminal cases where large stakes are at risk. Note in fact that even relatively short prison sentences carry a significant amount of stigma which has severe repercussions for lifetime earnings because of the psychological costs and the opportunity costs of the prison term, but also because the job-market opportunities are severely undercut (Funk, 2004). If this is true, then for criminal cases it makes sense to increase the burden of evidence in order to spare individuals from the risk of being wrongfully convicted which - as we have seen before - is the most expensive outcome in terms of utility that can happen to an individual. In other words, minimizing the social costs of crime implies minimizing the costs of errors (by moving $\tilde{e}$ ) and this in turn implies over-weighting wrongful convictions vis-à-vis wrongful acquittals because these are the most costly errors for the individual.

Conversely, civil cases often involve negligible amounts (at least with respect to income over a lifetime) and a good financial and insurance market can prevent and smooth most of these risks (note moreover that while it is generally possible to insure against losses in civil cases, this is generally ruled out in criminal cases). Therefore the assumption of standard utility risk aversion makes less

\footnotetext{
${ }^{20}$ On the error ratio, see additionally all the literature of previous papers and also a note of caution as explained byAllen and Pardo (2007); Allen and Laudan (2008).

${ }^{21}$ Of course the behaviors observed above can be justified instead under non-expected utility
} 
sense in civil law. The minimization of social costs - where the costs of wrongful convictions and wrongful acquittals are the same for deterrence - implies a smaller burden of proof.

\section{Appendix}

\subsection{The risk premium calculated with the Arrow-Pratt Absolute Risk Aversion}

For an individual willing to take an uncertain bet, the risk premium $R(y)$ is defined as the minimum difference between the expected value of a bet and the certainty equivalent he is indifferent to. The certainty equivalent $C E(y)$ is the guaranteed payoff at which a person is "indifferent" between accepting the guaranteed payoff and a higher but uncertain payoff. Therefore $R(y)=$ $U[E(y)]-C E[U(y)]$ (that is, the amount of the higher payout minus the risk premium). Because of the Jensen inequality we know that $U[E(y)] \leq E[U(y)]$, which implies the concavity of the utility function.

We also know that the Arrow-Pratt measure of absolute risk aversion (ARA) is $A(y)=\frac{U^{\prime \prime}(y)}{U^{\prime}(y)}$ and that risk premium and the Arrow-Pratt ARA measure are linked in the following way (see Cvitanic and Zapatero (2004, pg 112) and alsoGaroupa (1997)):

$$
R(y)=E(y)-C E(y) \approx \frac{1}{2} A R A(\pi) \operatorname{Var}[w]
$$

where $A R A(\pi)$ is the Arrow-Pratt ARA measure evaluated at the expected income $(\pi)$ level for the choice of action and $\operatorname{Var}[w]$ is the measure of the variance for the given choice of action. We use this to compute thus the risk premium of both staying within the law or committing the crime.

$$
\left\{\begin{array}{l}
R_{i}=\frac{1}{2} A R A\left(y_{0}-s\right) A_{i}\left(1-A_{i}\right) s^{2} \\
R_{g}=\frac{1}{2} A R A\left(y_{0}+b-s\right) A_{g}\left(1-A_{g}\right) s^{2}
\end{array}\right.
$$

and therefore the expected payoffs for staying within the law or committing the crime are:

$$
\left\{\begin{array}{l}
U E(y)_{i} \approx y_{0}-\left(1-A_{i}\right) s-\frac{1}{2} A R A\left(y_{0}-s\right) A_{i}\left(1-A_{i}\right) s^{2} \\
U E(y)_{g} \approx y_{0}+b-\left(1-A_{g}\right) s-\frac{1}{2} A R A\left(y_{0}+b-s\right) A_{g}\left(1-A_{g}\right) s^{2}
\end{array}\right.
$$

Now it is possible to compute the threshold $\tilde{b}$ : 


$$
\begin{aligned}
\tilde{b} \approx s\{\underbrace{\left(1-A_{g}\right)}_{I}[\underbrace{1+\frac{1}{2} A R A\left(y_{0}+b-s\right) A_{g} s}_{I I}] \\
\quad-\underbrace{\left(1-A_{i}\right)}_{I I I}[\underbrace{1+\frac{1}{2} A R A\left(y_{0}-s\right) A_{i} s}_{I V}]\}
\end{aligned}
$$

where term $I$ is the probability of conviction for the guilty defendant, term $I I$ adds also the risk premium of this option, term $I I I$ is the probability of conviction for the innocent defendant and term $I V$ adds also the risk premium for this option. Equation 13 can be also rewritten as $\tilde{b}=\left(A_{i}-A_{g}\right) s+R_{g}-R_{i}$.

The above equation states that the threshold $\tilde{b}$ depends on $s$ and on the capacity of the courts to discriminate between innocent and guilty people, also considering that these two options have a different level of risk.

Now we should use this threshold in computing our social costs.

$$
S W=\int_{\tilde{b}}^{B} R_{i}-R_{g}-h z(b) d b
$$

\section{References}

al Nowaihi, Ali and Sanjit Dhami, "Composite Prospect Theory: A proposal to combine 'prospect theory'and 'cumulative prospect theory'," Discussion Papers in Economics, 2010.

_ , Ian Bradley, and Sanjit Dhami, "A note on the utility function under prospect theory," Economics Letters, 2008, 99 (2), 337 - 339.

Allen, Ronald J. and Larry Laudan, "Deadly Dilemmas," Texas Tech Law Review, 2008, 41, 33.

- and Michael S. Pardo, "The Problematic Value of Mathematical Models of Evidence," Journal of Legal Studies, 2007, 36 (1), 107-140.

Alon, Harel and Klement Alon, "The Economics of Shame: Why More Shaming may Deter Less," Center for Rationality and Interactive Decision Theory, Hebrew University, Jerusalem, 2005.

Andreoni, James, "Reasonable Doubt and the Optimal Magnitude of Fines: Should the Penalty Fit the Crime?," The Rand Journal of Economics, 1991, 22 (3), 385-395. 
Battigalli, Pierpaolo and Martin Dufwenberg, "Guilt in Games," The American Economic Review, 2007, 97 (2), 170-176.

Baumeister, R.F., A.M. Stillwell, and T.F. Heatherton, "Guilt: An interpersonal approach.," Psychological Bulletin, 1994, 115 (2), 243.

Becker, Gary, "Crime and Punishment: An Economic Approach," Journal of Political Economy, 1968, 76, 169-217.

Blackstone, William, Commentaries on the laws of England., Vol. 4, Oxford: Clarendon Pr, 1769.

Bowles, Samuel, Microeconomics: behavior, institutions, and evolution, Princeton: Princeton University Press, 2004.

Craswell, Richard and John E. Calfee, "Deterrence and uncertain legal standards," Journal of Law, Economics, and Organization, 1986, 2 (2), 279303.

Cvitanic, J. and F. Zapatero, "Economics and Mathematics of Financial Markets," 2004

Dacey, Raymond and Kenneth S. Gallant, "Crime control and harassment of the innocent," Journal of Criminal Justice, 1997, 25 (4), 325-334.

Davis, Michael L., "The Value of Truth and the Optimal Standard of Proof in Legal Disputes," Journal of Law, Economics, and Organization, 1994, 10 (2), 343-359.

de Hooge, Ilona E., Marcel Zeelenberg, and Seger M. Breugelmans, "Moral sentiments and cooperation: Differential influences of shame and guilt," Cognition \& Emotion, 2007, 21 (5), 1025-1042.

Demougin, Dominique and Claude Fluet, "Deterrence versus Judicial Error: A Comparative View of Standards of Proof," Journal of Institutional and Theoretical Economics, 2005, 161 (2), 193-206.

_ and _ , "Preponderance of evidence," European Economic Review, 2006, 50 (4), 963-976.

_ and _ , "Rules of Proof, Courts, and Incentives," Presented at CESifo Area Conference on Applied Microeconomics, 2007.

Dhami, Sanjit and Ali al Nowaihi, "The Behavioral Economics of Crime and Punishment," Discussion Papers in Economics 10/14, Department of Economics, University of Leicester 2010.

Eide, Erling, "RDEU models of crime," Institutt for Privatrett University of Oslo, Working Paper Law and Economics C, 1995, 1. 
_, Kristine Von Simson, and Steinar Strom, "Rank-Dependent Utility, Tax Evasion, and Labor Supply," FinanzArchiv: Public Finance Analysis, 2011, 67 (3), 261-281.

Elster, Jon, "Emotions and Economic Theory," Journal of Economic Literature, 1998, 36 (1), 47-74.

Farmer, Amy and Dek Terrell, "Crime versus Justice: Is There a Tradeoff?," Journal of Law and Economics, 2001, 44 (2), 345-366.

Frank, R.H., Passions within reason: The strategic role of the emotions, WW Norton \& Co, 1988.

Franklin, Benjamin and Albert Henry Smyth, The writings of Benjamin Franklin, New York,: Haskell House, 1970.

Funk, Patricia, "On the effective use of stigma as a crime-deterrent," European Economic Review, 2004, 48 (4), 715-728.

Galbiati, Roberto and Nuno Garoupa, "Keeping Stigma Out of Administrative Law: An Explanation of Consistent Beliefs," Supreme Court Economic Review, 2007, 15.

Garoupa, Nuno, "The Theory of Optimal Law Enforcement," Journal of Economic Surveys, 1997, 11 (3), 267-295.

_ , "Crime and Punishment: Further Results," Economie Appliquee, 2001, 54 (3), 107-120.

- and Matteo Rizzolli, "Wrongful Convictions Do Lower Deterrence," Journal of Institutional and Theoretical Economics, 2013, 168, 224-231.

Harris, John R., "On the Economics of Law and Order," Journal of Political Economy, 1970, 78 (1), 165-174.

Hylton, Keith N. and Vikramaditya S. Khanna, "A Public Choice Theory of Criminal Procedure," Supreme Court Economic Review, 2007, 15, 61-118.

Kahan, Dan M., "What's Really Wrong with Shaming Sanctions," Texas Law Review, 2005-2006, 84, 2075-2096.

_ and Eric A. Posner, "Shaming White-Collar Criminals: A Proposal for Reform of the Federal Sentencing Guidelines," Journal of Law and Economics, 1999, 42 (1), 365-391.

Kahneman, Daniel J., "Maps of Bounded Rationality: Psychology for Behavioral Economics," The American Economic Review, 2003, 93 (5), 1449-1475.

- and Amos Tversky, "Prospect Theory: An Analysis of Decision under Risk," Econometrica, 1979, 47 (2), 263-292. 
_ , Jack L. Knetsch, and Richard H. Thaler, "Experimental Tests of the Endowment Effect and the Coase Theorem," Journal of Political Economy, 1990, 98 (6), 1325-1348.

Kahneman, Daniel, Jack L. Knetsch, and Richard H. Thaler, "The Endowment Effect, Loss Aversion, and Status Quo Bias: Anomalies," Journal of Economic Perspectives, 1991, 5 (1), 193-206.

Kaplow, Louis, "The Value of Accuracy in Adjudication: An Economic Analysis," Journal of Legal Studies, 1994, 23 (1), 307-401.

- and Steven Shavell, "Moral rules, the moral sentiments, and behavior: toward a theory of an optimal moral system," Journal of Political Economy, 2007, 115 (3), 494-514.

Kurzban, Robert, Peter DeScioli, and Erin O'Brien, "Audience effects on moralistic punishment," Evolution and Human Behavior, 2007, 28 (2), 75-84.

Lando, Henrik, "Does Wrongful Conviction Lower Deterrence?," Journal of Legal Studies, 2006, 35 (2), 327-338.

_ , "Prevention of Crime and the Optimal Standard of Proof in Criminal Law," Review of Law and Economics, 2009, 5 (1), 33-52.

Lattimore, Pamela and Ann Witte, "Models of decision making under uncertainty: The criminal choice," in "The reasoning criminal," Springer, 1986, pp. 129-155.

Lattimore, Pamela K., Joanna R. Baker, and Ann D. Witte, "The influence of probability on risky choice: A parametric examination," Journal of Economic Behavior \& Organization, 1992, 17 (3), 377 - 400.

Loewenstein, George, "Emotions in Economic Theory and Economic Behavior," The American Economic Review, 2000, 90 (2), pp. 426-432.

Massaro, Toni M., "The Meanings of Shame: Implications for Legal Reform," Psychology, Public Policy, and Law, 1997, 3 (4), 645-704.

McAdams, Richard H. and Eric B. Rasmusen, Norms in law and economics, Vol. 2, Amsterdam: North-Holland,

Miceli, Thomas J., "Optimal criminal procedure: Fairness and deterrence," International Review of Law and Economics, 1991, 11 (1), 3-10.

_, Criminal Procedure, edward elgar, chaltenham, uk ed., Vol. 3 of Criminal Law and Economics - Encyclopedia of Law $\mathcal{E}$ Economics, Edward Elgar Publishers, 2009.

Mitchell, Gregory, "Why Law and Economics' Perfect Rationality Should Not Be Traded for Behavioral Law and Economics' Equal Incompetence," Georgetown Law Journal, 2002, 91 (1), 67-168. 
Mookherjee, D and Ivan P. L. Png, "Monitoring vis-a-vis Investigation in Enforcement of Law," The American Economic Review, 1992, 82 (3), 556-565.

Neilson, William S and Harold Winter, "On criminals' risk attitudes," Economics Letters, 1997, 55 (1), 97-102.

Nussbaum, Martha Craven, Hiding from humanity : disgust, shame, and the law, Princeton, N.J.: Princeton University Press, 2004.

Ognedal, Tone, "Should the Standard of Proof Be Lowered to Reduce Crime?," International Review of Law and Economics, 2005, 25 (1), 45-61.

Persson, M. and C.H. Siven, "The Becker Paradox And Type I Versus Type Ii Errors In The Economics Of Crime," International Economic Review, 2007, $48(1), 211-233$.

Png, Ivan P. L., "Optimal Subsidies and Damages in the Presence of Judicial Error," International Review of Law and Economics, 1986, 6 (1), 101-05.

Polinsky, A. Mitchell and Steven Shavell, The Theory of Public Enforcement of Law, Amsterdam: Elsevier, 2007.

- and _ , Criminal Law and Economics - Encyclopedia of Law and Economics, Vol. 3, Amsterdam: Edward Elgar Pub.,

Polinsky, A.M. and S. Shavell, "The optimal tradeoff between the probability and magnitude of fines," The American Economic Review, 1979, pp. 880891.

Posner, Richard A., "An Economic Approach to the Law of Evidence," Stanford Law Review, 1999, 51 (6), 1477-1546.

Quiggin, J., "A theory of anticipated utility," Journal of Economic Behavior E Organization, 1982, 3 (4), 323-343.

_, Generalized expected utility theory: The rank-dependent model, Springer, 1993.

Rabin, Matthew, "Risk Aversion and Expected-Utility Theory: A Calibration Theorem," Econometrica, 2000, 68 (5), 1281-1292.

- and Richard H. Thaler, "Risk Aversion," Journal of Economic Perspectives, 2001, 15 (1), 219-232.

Rasmusen, Eric, "Stigma and Self-Fulfilling Expectations of Criminality," Journal of Law and Economics, 1996, 39 (2), 519-543.

Reiman, Jeffrey and Ernest van den Haag, "On the Common Saying That It Is Better That Ten Guilty Persons Escape Than That One Innocent Suffer: Pro and Con," Social Philosophi and Policy. Issue Crime, Culpability, and Remedy, 1990, 7 (2), 226. 
Reinganum, Jennifer F., "Plea Bargaining and Prosecutorial Discretion," The American Economic Review, 1988, 78 (4), 713-728.

Rizzolli, Matteo and Margherita Saraceno, "Better that ten guilty persons escape: punishment costs explain the standard of evidence," Public Choice, 2013, 155 (3-4), 395-411. 10.1007/s11127-011-9867-y.

Rubinfeld, Daniel L. and David E. M. Sappington, "Efficient Awards and Standards of Proof in Judicial Proceedings," RAND Journal of Economics, 1987, 18 (2), 308-315.

Sanchirico, Chistian W., "The burden of proof in civil litigation: A simple model of mechanism design," International Review of Law and Economics, 1997, $17(3), 431-447$.

Schauer, Frederick and Richard Zeckhauser, "On the Degree of Confidence for Adverse Decisions," Journal of Legal Studies, 1996, 25, 27.

Schrag, Joel and Suzanne Scotchmer, "Crime and prejudice: The use of character evidence in criminal trials," Journal of Law, Economics, and Organization, 1994, 10 (2), 319-342.

Tversky, A. and D. Kahneman, "Advances in prospect theory: Cumulative representation of uncertainty," Journal of Risk and Uncertainty, 1992, 5 (4), $297-323$.

Vanberg, Viktor J., "On the Economics of Moral Preferences," American Journal of Economics and Sociology, 2008, 67 (4), 605-628.

Volokh, Alexander, "n Guilty Men," University of Pennsylvania Law Review, 1997, 146 (1), 173-216.

Yilankaya, Okan, "A Model of Evidence Production and Optimal Standard of Proof and Penalty in Criminal Trials," Canadian Journal of Economics, 2002, 35 (2), 385-409. 